\title{
Carnitine palmitoyl transferase 1A deficiency
}

INSERM

\section{Source}

INSERM. (1999). Orphanet: an online rare disease and orphan drug data base. Carnitine palmitoyl transferase 1A deficiency. ORPHA:156

Carnitine palmitoyltransferase $1 \mathrm{~A}(\mathrm{CPT}-1 \mathrm{~A})$ deficiency is an inborn error of metabolism that affects mitochondrial oxidation of long chain fatty acids (LCFA) in the liver and kidneys, and is characterized by recurrent attacks of fasting-induced hypoketotic hypog lycemia and risk of liver failure. 